Article

\title{
Clinical Prediction of Type 2 Diabetes Mellitus (T2DM) via Anthropometric and Biochemical Variations in Prakriti
}

\author{
Shriti Singh ${ }^{1, *}$, Neeraj Kumar Agrawal ${ }^{2}{ }^{(}$, Girish Singh ${ }^{3}$, Sangeeta Gehlot ${ }^{1}$, Santosh Kumar Singh ${ }^{4}(\mathbb{D}$ \\ and Rajesh Singh $4, * \mathbb{D}$
}

1 Department of Kriya Sharir, Faculty of Ayurveda, Institute of Medical Sciences, Banaras Hindu University, Varanasi 221005, India; sangeetagehlot@gmail.com

2 Department of Endocrinology and Metabolism, Institute of Medical Sciences, Banaras Hindu University, Varanasi 221005, India; drnkavns@gmail.com

3 Centre of Biostatistics, Institute of Medical Sciences, Banaras Hindu University, Varanasi 221005, India; drgirishsingh@yahoo.com

4 Department of Microbiology, Biochemistry, and Immunology, Cancer Health Equity Institute, Morehouse School of Medicine, 720 Westview Drive SW, Atlanta, GA 30310, USA; sksingh@msm.edu

* Correspondence: singhshriti@gmail.com (S.S.); rsingh@msm.edu (R.S.); Tel.: +1-404-756-6661 (R.S.); Fax: +1-404-752-1179 (R.S.)

check for

updates

Citation: Singh, S.; Agrawal, N.K.;

Singh, G.; Gehlot, S.; Singh, S.K.;

Singh, R. Clinical Prediction of Type 2

Diabetes Mellitus (T2DM) via

Anthropometric and Biochemical

Variations in Prakriti. Diseases 2022,

10, 15. https://doi.org/10.3390/

diseases 10010015

Academic Editors: Marwan El Ghoch and Agnes Ayton

Received: 25 January 2022

Accepted: 1 March 2022

Published: 3 March 2022

Publisher's Note: MDPI stays neutral with regard to jurisdictional claims in published maps and institutional affiliations.

Copyright: (C) 2022 by the authors. Licensee MDPI, Basel, Switzerland. This article is an open access article distributed under the terms and conditions of the Creative Commons Attribution (CC BY) license (https:// creativecommons.org/licenses/by/ $4.0 /)$.

\begin{abstract}
Type 2 Diabetes Mellitus (T2DM) is a complicated multifactorial illness involving hereditary and external environmental variables. The symptoms typically appear gradually over a number of years without realizing it. This viewpoint is further supported by the Ayurvedic constitution concept (Prakriti). Prakriti explains the biological variability that is observed in different individuals. This study was conducted a retrospective investigation to examine if there was a link between type 2 diabetes and an individual's constitution based on anthropometric and biochemical characteristics. Physical and mental characteristics and anthropometric and biochemical markers were used to determine reported cases' prevailing Dosha Prakriti (constitution). Based on biochemical and anthropometric data, significant differences in Prakriti were found between the case (T2DM patients) and control (person without diabetes) groups. The incidence of numerous secondary problems linked with T2DM patients was also evaluated according to their Prakriti types, which revealed a positive relationship. The three primary contributing parameters, such as waist-hip ratio, postprandial blood sugar, and serum creatinine, were correctly classified all person with or without diabetes subjects to $90.6 \%$ of the time, whereas the constitution-wise study classified person with diabetes and without diabetes individuals of Pitta and Kapha Prakriti to $94.3 \%$ and $90 \%$, respectively. A discriminant function was created to predict a person with diabetes and without diabetes based on these three contributing factors. The primary contributing biochemical parameters discovered by Prakriti in the current study could be used as a biochemical disease diagnostic for predicting type 2 diabetes susceptibility.
\end{abstract}

Keywords: Vata; Pitta; Kapha; biochemical marker; T2DM; anthropometric parameters

\section{Introduction}

Diabetes mellitus (DM) is wreaking havoc on the public health system. DM is linked to an elevated risk of numerous types of diseases and malignancies [1]. The disease's prevalence is anticipated to rise to 623 million by 2045, with type 2 diabetes mellitus (T2DM) accounting for about $90 \%$ of cases [2]. Hyperglycemia is a symptom of T2DM caused by insulin resistance and a decrease in insulin production. It is a common disorder with increasing prevalence due to lack of physical activity and increased degrees of obesity [3]. Insulin resistance is a condition that affects body cells such as the muscle, liver, and fat cells; consequently, they fail to respond to insulin, even when insulin levels are high. In fat cells, triglycerides are broken down to produce free fatty acids for energy; muscle cells are deprived of energy sources, and liver cells fail to build up glycogen stores. Several 
factors impede understanding of the pathophysiology of type 2 diabetes [4]. In diabetes mellitus, hyperglycemia initiates and sustains an injury to many organs and systems, resulting in serious complications such as retinopathy, neuropathy, cardiovascular diseases, nephropathy, peripheral vascular diseases, and periodontal pathologies [5].

Ayurveda is an ancient Indian healing system that uses a personalized approach that has been documented and practiced for thousands of years. Ayurveda has a unique classification of the human population based on the individual constitution or Prakriti [6]. The Tridosha theory of Ayurveda's recognizes principles of movement (Vata), metabolism (Pitta), and strength (Kapha) as distinct phenotypic groupings. As per this system, every individual is born with their basic constitution, which determines to a great extent inter-individual variability in susceptibility to diseases and response to the external environment, diet, and drugs. According to Ayurveda, there are five elements (panchmahabhoot) Aakash (space), Jala (water), Agni (fire), Prithvi (earth), and Vayu (air); its combination is responsible for the formation of dosha, i.e., Vata (air and space), Pitta (fire and water), Kapha (water and earth). Because dosha balance is a sign of good health and imbalance is a sign of disease, each person's dosha proportion is different. According to Ayurveda, an individual's Prakriti, or constitution, is determined by the relative predominance of Vata, Pitta, and Kapha. Prakriti refers to the sum of all physical, physiological, and psychological traits. People with different Prakriti types react differently to the same stimuli. Prakriti has been extensively studied to understand better its genomic and biochemical correlations [7-9]. The prior knowledge of Prakriti of individuals/patients helps suggest lifestyle modifications in patients. According to Ayurveda, the manifestation of diabetes occurs due to Kapha's predominant diet, such as sweets, curd, newly harvested grains, etc. As a result, the knowledge of patients' dominant Dosha Prakriti aids in diagnosis, prognosis, and treatment of their disease. Ayurveda describes DM under non-insulin-dependent DM as Kaphaj and Pittaj Prameha; it represents early diabetes and acute diabetes. Based on complications associated with the chronic stage of the disease, the same T2DM condition is termed Vataja Prameha/Madhumeha. Similarly, insulin-dependent DM has also been defined under Vataja Prameha [10]. Prakriti types exhibit striking differences in biochemical and hematological parameters [11].

The present study focused on determining the prevalence of dominant Prakriti in T2DM patients in relation to their anthropometric and biochemical variables.

\section{Material and Methods}

\subsection{Sample Size}

The sample size was determined by estimating some key variables from previous research [12,13]. The sample size was calculated using relevant anthropometric and biochemical parameters, with alpha set at $5 \%$ and power set at $90 \%$. A total of 112 subjects for the case and 112 subjects for the control group were the final sample size for the study.

\subsection{Design}

This study included 112 persons with diabetes who visited the outpatient section of the Endocrine and Metabolism department existing in Sir Sunderlal Hospital, Institute of Medical Sciences, Banaras Hindu University (B.H.U.), Varanasi, India, and 112 healthy (control subjects) volunteers were drawn from B.H.U employee's community from different departments. The research was carried out with random selection between February 2016 and April 2017. All the subjects were registered after obtaining their written consent. Prakriti assessment was carried out by a questionnaire developed by Tripathi et al. 2019 [14] The short description of the Prakriti assessment tool is shown in Supplementary Table S1. The characteristics of Vata, Pitta, and Kapha dominant Prakritis were studied according to Ayurvedic scriptures. Research work has been approved by the Institutional Ethics Committee vide letter No. Dean/2015-2016/1572 dated 30 December 2015. 


\subsection{Criteria of Subject Selection}

Subjects of both sexes over the age of 40 years were registered. Informed written consent was taken from them.

\subsubsection{Selection of Diabetic Subjects Was Based on the Following Criteria}

(i) Fasting blood glucose value $126 \mathrm{mg} / \mathrm{dL}$ or higher.

(ii) Post Prandial blood glucose level more than $200 \mathrm{mg} / \mathrm{dL}$.

(iii) No insulin-dependent cases (type 1 diabetes).

Fasting blood glucose value was measured two times. Additionally, $75 \mathrm{~g}$ OGTT (Oral Glucose Tolerance Test) was conducted. Additionally, the blood samples were collected after $2 \mathrm{~h}$ of the meal. All tests were conducted in the Center for Clinical Investigation (CCI) Laboratory, Banaras Hindu University, India.

\subsubsection{Selection of Control Subjects}

(i) No family history of type 2 diabetes (because of this, there are genetically fewer chances to have predisposition with the disease).

(ii) Blood glucose level within the normal range, i.e., Fasting and Postprandial. (It shows glucose metabolism and insulin action were proper; hence no hyperglycemia was detected).

(iii) Healthy individuals, not under any medication, were considered. (Biochemical parameters may be affected due to intake of medication).

\subsubsection{Exclusion Criteria}

(i) Unwilling participants.

(ii) Patients with insulin-dependent DM, tuberculosis, AIDS, and malignancies were excluded.

Cases of diagnosed T2DM in both sexes ranging in age from 40 to 70 years were chosen randomly from February 2016-April 2017. For the Prakriti assessment of T2DM patients, pre diseased conditions of their health and habits were considered. Clinically type 2 diabetes persons have been considered a case for the study, whereas clinically, persons without diabetes acted as a control. For this study, the standard criteria of the American diabetic association 2015 for diabetes were adopted. A $3 \mathrm{~mL}$ blood sample from the antecubital vein was collected from each case and control subjects in an EDTA vial.

\subsubsection{Limitations}

The study covers only a small population of eastern Uttar Pradesh, India. The laboratory made all tests and patients came up with a report. In the future, to obtain more precise results, the study may be conducted with a large sample size, and samples may be collected from a different area of the country or worldwide.

\subsection{Parameters Associated with Study}

Various anthropometric, biochemical, and physiological parameters were adopted for case and control subjects under study. Height, weight, BMI, and waist-hip ratio were taken as anthropometric parameters while blood pressure was used as a physiological criterion; in contrast, blood sugar fasting, postprandial fasting lipid profile, and serum creatinine were assessed under biochemical parameters. eGFR was calculated by online software through the Modification of Diet in Renal Disease (MDRD) study equation for estimating the risk of kidney damage. For T2DM individuals, HbA1c and ECG were also recorded. Further investigating any secondary complication in T2DM cases, retinopathy, neuropathy, family history, and macro proteinuria were evaluated.

\subsection{Statistics}

Prakriti-based statistical analysis of clinical data was performed. Data were represented as Mean \pm SD. Because just one subject of Vata Prakriti was recorded in T2DM cases, 
it was excluded from the statistical analysis, and only Pitta and Kapha Prakriti samples were used. In the present study, for T2DM cases, the independent group $t$-test was applied. For the control group, one-way ANOVA was used, and to observe the significance among different Prakriti groups; the Post hoc test was applied. Bonferroni test was applied following ANOVA. For secondary complications in the case group, i.e., Neuropathy, Retinopathy and family history of CVD, etc., their association with Prakriti was determined by the chi-square test, which shows the significance of incidence among different Prakriti. $p$-values $<0.05$ were considered for statistical significance in all the statistical analyses. Discriminant function analysis was applied to see major contributing parameters in Pitta and Kapha Prakriti related to disease in the case and control group.

\section{Results}

Among a total of 112 T2DM cases, Pitta $(\mathrm{n}=51)$ and Kapha $(\mathrm{n}=60)$ individuals were grouped according to the dominance of their Dosha Prakriti. Patients with Kapha Prakriti were found to be more than those with Pitta Prakriti and Vata Prakriti ( $\mathrm{n}=1)$. Similarly, 112 persons without diabetes were grouped into Vata $(\mathrm{n}=17)$, Pitta $(\mathrm{n}=55)$, and Kapha $(n=40)$ based on their dominance of Dosha Prakriti. In individuals with diabetes, the average value of age was found 52.9 years, and for control individuals, it was 50.2 years. Gender proportion for persons with diabetes females $(n=41) 37 \%$ and diabetes males $(n=70) 63 \%$ and in persons without diabetes females $(n=26) 23 \%$ and males $(n=86) 77 \%$. The average duration of suffering from diabetes was 5.8 years in patients.

Among finding associated with Prakriti-based anthropometric and biochemical parameters for type 2 diabetes patients, they showed statistically significant differences in parameters, i.e., weight, Basal Metabolic Index (BMI), waist-hip ratio, fasting, and postprandial blood sugar, systolic blood pressure, total cholesterol, HDL and LDL, between Kapha and Pitta Prakriti. Despite the fact that the mean values of height, serum triglyceride, serum creatinine levels, and $\mathrm{HbA1c}$ were greater in Kapha Prakriti, diastolic blood pressure, and eGFR values were higher in Pitta Prakriti; there was no statistically significant difference found between the two Prakriti (Table 1).

Table 1. Showing anthropometric and biochemical parameters of type 2 diabetes subjects as per Prakriti.

\begin{tabular}{ccccc}
\hline Parameters & $\begin{array}{c}\text { Pitta }(\mathbf{n}=\mathbf{5 1}) \\
\text { (Mean } \pm \text { SD) }\end{array}$ & $\begin{array}{c}\text { Kapha }(\mathbf{n}=\mathbf{6 0}) \\
\text { (Mean } \pm \text { SD) }\end{array}$ & t-Test & $p$-Value \\
\hline Height $(\mathrm{cm})$ & $158 \pm 7$ & $160 \pm 10$ & 1.1 & 0.26 \\
\hline Weight $(\mathrm{kg})$ & $64 \pm 11$ & $71 \pm 10$ & 3.5 & 0.001 \\
\hline BMI $\left(\mathrm{kg} / \mathrm{m}^{2}\right)$ & $26 \pm 4$ & $28 \pm 4$ & 2.8 & 0.006 \\
\hline Systolic Blood Pressure $(\mathrm{mm}$ of $\mathrm{Hg})$ & $135 \pm 16$ & $124 \pm 6$ & 5.1 & $<0.001$ \\
\hline Diastolic Blood Pressure $(\mathrm{mm}$ of $\mathrm{Hg})$ & $82 \pm 10$ & $79 \pm 8.7$ & 1.5 & 0.14 \\
\hline Waist Hip Ratio $(\mathrm{cm})$ & $0.9 \pm 0.05$ & $0.96 \pm 0.05$ & 8.2 & $<0.001$ \\
\hline Fasting Blood Sugar $(\mathrm{mg} / \mathrm{dL})$ & $142 \pm 31$ & $183 \pm 78$ & 3.5 & 0.001 \\
\hline Post Prandial Blood Sugar $(\mathrm{mg} / \mathrm{dL})$ & $220 \pm 64$ & $290 \pm 112$ & 3.9 & $<0.001$ \\
\hline HDL $(\mathrm{mg} / \mathrm{dL})$ & $39 \pm 7$ & $44 \pm 8$ & 3.1 & 0.002 \\
\hline LDL $(\mathrm{mg} / \mathrm{dL})$ & $107 \pm 43$ & $126 \pm 38$ & 2.5 & 0.01 \\
\hline Triglyceride $(\mathrm{mg} / \mathrm{dL})$ & $137 \pm 60$ & $164 \pm 69$ & 1.9 & 0.05 \\
\hline Total Cholesterol $(\mathrm{mg} / \mathrm{dL})$ & $167 \pm 45$ & $189 \pm 40$ & 2.7 & 0.007 \\
\hline SerumCreatinine $(\mathrm{mg} / \mathrm{dL})$ & $0.95 \pm 0.30$ & $0.99 \pm 0.31$ & 0.7 & 0.48 \\
\hline eGFR * (mL/min/1.73 m $\left.{ }^{2}\right)$ & $83 \pm 40$ & $77 \pm 26$ & 0.9 & 0.38 \\
\hline HbA1C $(\%)$ & $8 \pm 1.6$ & $8 \pm 2$ & 1.0 & 0.31 \\
\hline *GFR—Glomerular Filtration Rate & & &
\end{tabular}

* GFR-Glomerular Filtration Rate. 
A statistically significant difference was found in BMI, systolic and diastolic blood pressure, fasting and postprandial blood sugar, LDL, triglyceride, total cholesterol, serum creatinine, and eGFR parameters when compared anthropometric and biochemical parameters in individuals with diabetes cases and without diabetes control group individuals belonging to the Kapha-dominant Prakriti. Similarly, in Pitta-dominant Prakriti individuals with diabetes, and in non-diabetics, their weight, systolic and diastolic blood pressure, fasting and postprandial blood sugar, serum creatinine, and eGFR parameters showed statistically significant differences (data shown in Supplementary Tables S2 and S3).

No significant difference was found in secondary complications associated with T2DM between the Prakriti groups. Based on mean values, this study observed that more patients have cardiovascular problems than those belonging to Kapha Prakriti than Pitta Prakriti. The incidence of retinopathy, neuropathy and micro and macro proteinuria differed significantly between Pitta and Kapha Prakrit patients. In contrast, the incidence of family history of cardiovascular disease and family history of diabetes showed a higher correlation in patients of Kapha Prakriti, i.e., 25\% and 53\%, respectively, whereas in patients with Pitta Prakriti, these incidences were $45.1 \%$ and $19.6 \%$, respectively. At the same time, no significant differences were observed among them (Table 2).

Table 2. Showing secondary complications and family history of the person with diabetes as per Prakriti.

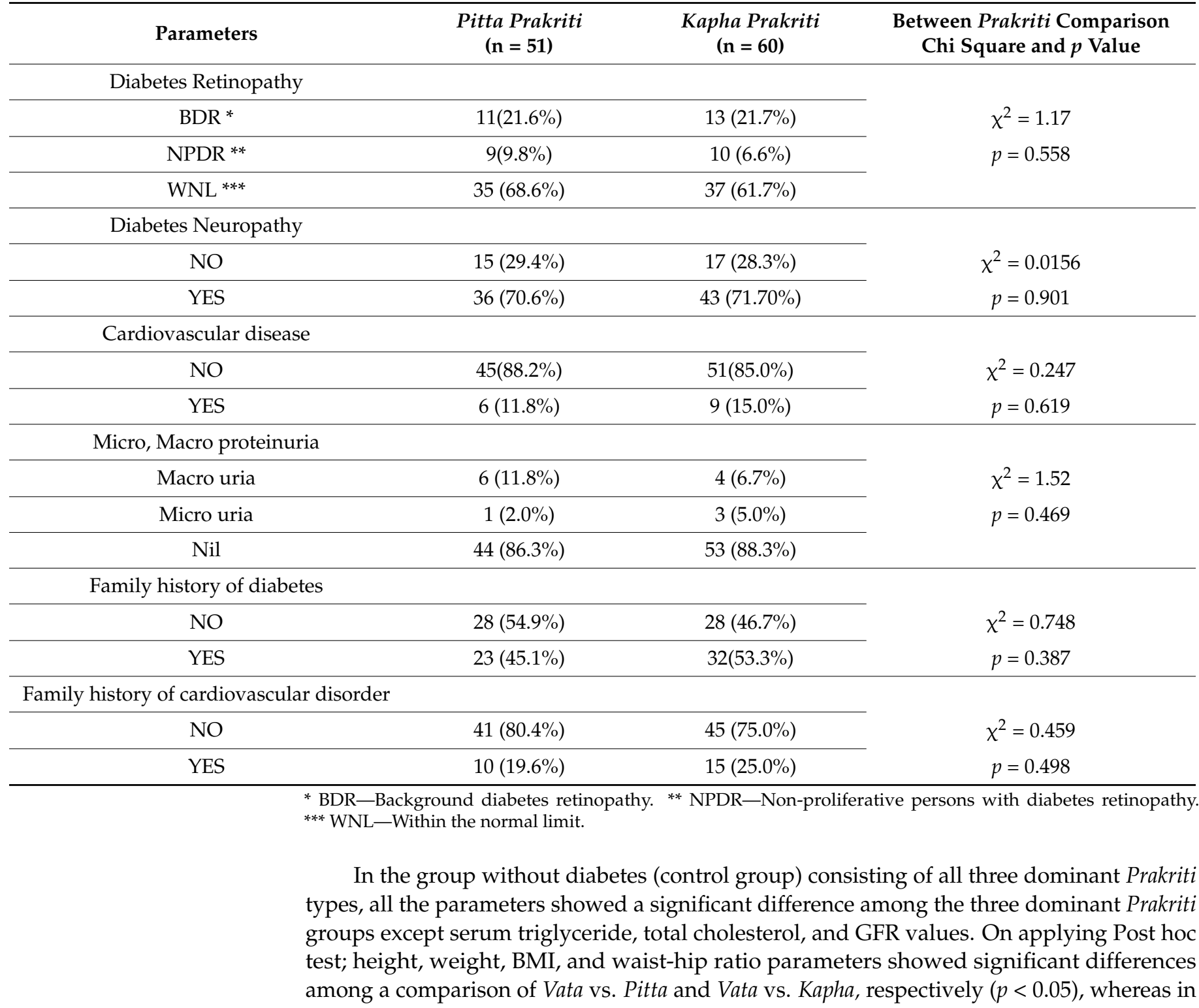


Pitta vs. Kapha comparison, Prakriti individuals did not show a significant difference for parameters as mentioned below (Table 3). Systolic and diastolic blood pressure showed significant variations in all the combinations of the Prakriti group. In fasting blood sugar, a significant difference was noted in all pair-wise comparisons of Prakriti, i.e., Vata vs. Pitta, Pitta vs. Kapha, Vata vs. Kapha, whereas in postprandial blood sugar, the comparison of Vata vs. Pitta Prakriti did not show a significant difference. There was no significant difference between HDL levels in the Vata vs. Pitta combination in the fasting lipid profile.

On the other hand, Vata vs. Kapha and Pitta vs. Kaph showed a substantial difference. A significant difference was found in LDL among Vata vs. Kapha and Pitta vs. Kapha Prakriti individuals $(p<0.05)$. No significant difference was found in total cholesterol, triglyceride, and eGFR in any combination of Prakriti. In contrast, a significant difference was noted in serum creatinine values for Vata vs. Pitta and Vata vs. Kapha Prakriti groups (Table 3).

Discriminant function analysis was carried out on the case (persons with diabetes) vs. control group (without diabetes), based on some important biochemical parameters. Among all the parameters considered in the present study, the three parameters were major contributing, e.g., waist-hip ratio, postprandial blood sugar, serum creatinine, which resulted in a $90.6 \%$ correct classification of all cases and control subjects. The standardized canonical discriminant function coefficient of waist-hip ratio (WHR), postprandial blood sugar (PPBS), and serum creatinine (Scr) for total subjects were 0.290, 0.973, and 0.622, respectively. The classification function coefficients are as follows:

$$
\begin{gathered}
\mathrm{F}_{\text {Totalcase }}=-87.669+161.368 \mathrm{WHR}+0.045 \mathrm{PPBS}+13.16 \mathrm{Scr} \\
\mathrm{F}_{\text {Totalcontrol }}=-84.355+171.303 \mathrm{WHR}+0.010 \mathrm{PPBS}+6.255 \mathrm{Scr}
\end{gathered}
$$

The subjects were classified, i.e., individuals with diabetes (cases) or without diabetes (control), based on higher values among the above two functions. The discriminant function analysis was carried out on different Prakriti individuals (Pitta and Kapha) (data shown in Supplementary Tables S2 and S3). These three above-mentioned significant contributors showed correct classification for Pitta and Kapha Prakriti individuals in the present study by the value of $94.3 \%$ and $90.0 \%$, respectively. The standardized canonical discriminant function coefficient of waist-hip ratio (WHR), postprandial blood sugar (PPBS), and serum creatinine (Scr) for Pitta Prakriti individuals were 0.530, 0.908, 0.483, respectively, whereas for Kapha Prakriti, it was 0.100, 1.031, 0.678, respectively.

The classification function coefficient for Pitta Prakriti is as follows:

$$
\begin{gathered}
\mathrm{F}_{\text {Pitta case }}=-102.429+197.221 \mathrm{WHR}+0.085 \mathrm{PPBS}+11.062 \mathrm{Scr} \\
\mathrm{F}_{\text {Pitta control }}=-108.854+221.572 \mathrm{WHR}+0.024 \mathrm{PPBS}+4.457 \mathrm{Scr}
\end{gathered}
$$

The classification function coefficient for Kapha Prakriti is as follows:

$$
\begin{gathered}
\mathrm{F}_{\text {Kapha case }}=-122.037+208.069 \mathrm{WHR}+0.81 \mathrm{PPBS}+19.07 \mathrm{Scr} \\
\mathrm{F}_{\text {Kapha control }}=-106.443+204.455 \mathrm{WHR}+0.051 \mathrm{PPBS}+12.323 \mathrm{Scr}
\end{gathered}
$$

By comparing function coefficient for Kapha and Pitta Prakriti, we found that as compared with postprandial blood sugar and serum creatinine, the contribution of the waist-hip ratio was lower for Kapha Prakriti individuals as compared with Pitta Prakriti, it shows that the difference between the values of the waist-hip ratio of the Kapha Prakriti case (persons with diabetes) and control (group without diabetes) is smaller than that of Pitta Prakriti case and control. Similarly, serum creatinine contributes less to Pitta Prakriti than Kapha Prakriti, showing less difference between case and control values for this parameter in Pitta Prakriti. 
Table 3. Showing anthropometric and biochemical parameters of the group without diabetes subjects as per Prakriti.

\begin{tabular}{|c|c|c|c|c|c|c|}
\hline Parameters & $\begin{array}{l}\text { Vata Prakriti } \\
\quad(\mathrm{n}=\mathbf{1 7}) \\
\text { Mean } \pm \mathrm{SD}\end{array}$ & $\begin{array}{c}\text { Pitta Prakriti } \\
\quad(\mathrm{n}=55) \\
\text { Mean } \pm \text { SD }\end{array}$ & $\begin{array}{c}\text { Kapha Prakriti } \\
(\mathrm{n}=40) \\
\text { Mean } \pm \text { SD }\end{array}$ & $\mathbf{F}$ & $p$-Value & Post hoc Test $(<0.05)$ \\
\hline Height (cm) & $157 \pm 8$ & $163 \pm 8$ & $165 \pm 6$ & 8.752 & $<0.0001$ & $\begin{array}{c}\text { Vata vs. Pitta } 0.004 \\
\text { Vata vs. Kapha }<0.001 \\
\text { Pitta vs. Kapha } 0.480\end{array}$ \\
\hline Weight (kg) & $55 \pm 10$ & $63 \pm 10$ & $68 \pm 10$ & 140.00 & $<0.0001$ & $\begin{array}{c}\text { Vata vs. Pitta }<0.001 \\
\text { Vata vs. Kapha }<0.001 \\
\text { Pitta vs. Kapha } 1.000\end{array}$ \\
\hline $\operatorname{BMI}\left(\mathrm{kg} / \mathrm{m}^{2}\right)$ & $22 \pm 3$ & $24 \pm 3$ & $25 \pm 3$ & 9.779 & $<0.0001$ & $\begin{array}{l}\text { Vata vs. Pitta }<0.001 \\
\text { Vata vs. Kapha } 0.009 \\
\text { Pitta vs. Kapha } 0.300\end{array}$ \\
\hline $\begin{array}{l}\text { Systolic Blood Pressure } \\
(\mathrm{mm} \text { of } \mathrm{Hg})\end{array}$ & $126 \pm 4$ & $118 \pm 4$ & $115 \pm 4$ & 56.003 & $<0.0001$ & $\begin{array}{c}\text { Vata vs. Pitta }<0.001 \\
\text { Vata vs. Kapha }<0.001 \\
\text { Pitta vs. Kapha } 0.001\end{array}$ \\
\hline $\begin{array}{l}\text { Diastolic Blood Pressure } \\
\qquad(\mathrm{mm} \text { of } \mathrm{Hg})\end{array}$ & $87 \pm 3$ & $79 \pm 4$ & $76 \pm 4$ & 46.361 & $<0.0001$ & $\begin{array}{c}\text { Vata vs. Pitta }<0.001 \\
\text { Vata vs. Kapha }<0.001 \\
\text { Pitta vs. Kapha } 0.019\end{array}$ \\
\hline Waist Hip Ratio (cm) & $0.9 \pm 0.06$ & $0.9 \pm 0.08$ & $0.95 \pm 0.09$ & 4.943 & 0.009 & $\begin{array}{l}\text { Vata vs. Pitta } 0.018 \\
\text { Vata vs. Kapha } 0.009 \\
\text { Pitta vs. Kapha } 1.000\end{array}$ \\
\hline $\begin{array}{l}\text { Blood Sugar }(\mathrm{mg} / \mathrm{dL}) \\
\text { Fasting }\end{array}$ & $83 \pm 5$ & $91 \pm 8$ & $97 \pm 8$ & 22.762 & $<0.0001$ & $\begin{array}{c}\text { Vata vs. Pitta } 0.001 \\
\text { Vata vs. Kapha }<0.001 \\
\text { Pitta vs. Kapha }<0.001\end{array}$ \\
\hline $\begin{array}{l}\text { Blood Sugar }(\mathrm{mg} / \mathrm{dL}) \\
\text { Post Prandial }\end{array}$ & $109 \pm 6$ & $116 \pm 10$ & $123 \pm 15$ & 9.758 & $<0.0001$ & $\begin{array}{c}\text { Vata vs. Pitta } 0.072 \\
\text { Vata vs. Kapha }<0.001 \\
\text { Pitta vs. Kapha } 0.015\end{array}$ \\
\hline $\mathrm{HDL}(\mathrm{mg} / \mathrm{dL})$ & $39 \pm 3$ & $41 \pm 4$ & $44 \pm 4$ & 10.683 & $<0.0001$ & $\begin{array}{c}\text { Vata vs. Pitta } 0.169 \\
\text { Vata vs. Kapha }<0.001 \\
\text { Pitta vs. Kapha } 0.003\end{array}$ \\
\hline $\mathrm{LDL}(\mathrm{mg} / \mathrm{dL})$ & $94 \pm 22$ & $97.78 \pm 18.50$ & $99 \pm 20$ & 0.354 & 0.703 & $\begin{array}{c}\text { Vata vs. Pitta } 0.169 \\
\text { Vata vs. Kapha }<0.001 \\
\text { Pitta vs. Kapha } 0.003\end{array}$ \\
\hline Triglyceride (mg/dL) & $116 \pm 9$ & $122 \pm 12$ & $125 \pm 14$ & 2.573 & 0.081 & $\begin{array}{l}\text { Vata vs. Pitta } 1.000 \\
\text { Vata vs. Kapha } 1.000 \\
\text { Pitta vs. Kapha } 1.000\end{array}$ \\
\hline Total cholesterol (mg/dL) & $149 \pm 24$ & $161 \pm 17$ & $165 \pm 18$ & 3.861 & 0.024 & $\begin{array}{c}\text { Vata vs. Pitta } 0.290 \\
\text { Vata vs. Kapha } 0.076 \\
\text { Pitta vs. Kapha } 1.000\end{array}$ \\
\hline Serum creatinine (mg/dL) & $0.73 \pm 0.08$ & $0.79 \pm 0.08$ & $0.80 \pm 0.07$ & 6.224 & 0.003 & $\begin{array}{c}\text { Vata vs. Pitta } 0.007 \\
\text { Vata vs. Kapha } 0.003 \\
\text { Pitta vs. Kapha } 1.000\end{array}$ \\
\hline $\mathrm{eGFR} *\left(\mathrm{~mL} / \mathrm{min} / 1.73 \mathrm{~m}^{2}\right)$ & $98 \pm 8$ & $99 \pm 7$ & $100 \pm 8$ & 0.648 & 0.525 & $\begin{array}{l}\text { Vata vs. Pitta } 1.000 \\
\text { Vata vs. Kapha } 0.825 \\
\text { Pitta vs. Kapha } 1.000\end{array}$ \\
\hline
\end{tabular}

* GFR-Glomerular filtration rate.

\section{Discussion}

The Prakriti of patients determines the majority of diseases and their clinical manifestations. According to Ayurveda, Vata, Pitta, and Kapha (Tridosha) regulate all the physiological processes in the body. It also directly relates to an individual's ability to fight sickness. The equilibrium of Tridoshas leads to perfect health, and disharmony leads to the diseased 
condition. In this study, the Vata Prakriti cases for type 2 diabetes were not encountered much. Only one case was found; this might be because only chronic cases of T2DM become converted into Vatic Prameha or type1 diabetes case where patients are completely insulin dependent as reported by Sharma and Chandola 2011 [10]. Individuals with diabetes and without diabetes in the present study were of similar age groups, which was over 40 years of age; the American Diabetes Association (ADA) recommends annual diabetes screening tests after people reach the age of above forty. The T2DM participants were Pitta and Kapha Prakriti. Height, weight, BMI, and waist-hip ratio were higher in Kapha Prakriti individuals than Pitta (Table 1). According to Charak, Kapha Prakriti individuals have a well-built and strong body than other Prakriti individuals [15]. The waist-hip ratio and BMI are both associated with insulin resistance [16], which is linked to T2DM. In Kapha Prakriti's individuals, BMI and waist-hip ratio were higher above the physiological limit. In the Kapha Prakriti subjects, fasting and postprandial blood sugar were also higher, with a range of $182.90 \pm 77.70$ and $289.63 \pm 112.13$, respectively. T2DM is mainly Kapha dominant metabolic disorder in which digestive power becomes imbalanced, leading to toxin formation (Aama) in the body and ultimately causing improper glycemic control [12].

In people with diabetes, blood pressure is lower in Kapha Prakriti than in Pitta Prakriti, whereas lipid profile levels are more noteworthy in Kapha Prakriti than in Pitta Prakriti. In research by Amin et al. (2015), persons with Kapha-dominant Prakriti had a more extensive range (within normal limits) of cholesterol, triglycerides, VLDL, HDL, and LDL [17]. Serum creatinine is found higher in Kapha Prakriti individuals than Pitta Prakriti; this is because in Kapha Prakriti, aama formation due to impaired digestion and metabolism may lead to a higher level of serum creatinine [12]. In the present study, HbA1c was also found slightly higher in Kapha Prakriti persons but did not show a significant difference with Pitta Prakriti individuals. Additionally, Ayurveda addresses that Rakta (blood) and Pitta complement each other [18]. These studies suggest a higher hemoglobin level in Pitta than Kapha and Vata Prakriti.

The Prakriti of individuals is fixed, just like our genetic setup. This influences an individual's physiological, physical, and psychological aspects, either in a healthy condition or in a diseased state. This is what the current study attempted to investigate. We found T2DM patients with Pitta and Kapha Prakriti exhibited differences in the parameters used for analysis in the same disease condition, confirming the above premise of Prakriti-based variances in distinct Prakriti types.

Secondary complications associated with type 2 diabetes patients (Table 2) revealed a higher incidence of cardiovascular disorder (CVD), a family history of diabetes, and a family history of CVD in Kapha Prakriti individuals than in Pitta Prakriti. In contrast, the incidence of neuropathy, retinopathy, and micro and macro proteinuria was similar in Pitta and Kapha Prakriti.

Furthermore, Mahalle et al. (2012) have reported a strong relationship between cardiovascular disease or risk factors with Vata Kaph and Kapha Prakriti [19]. The presence of other microvascular complications, such as nephropathy or retinopathy acting as a risk factor for people with diabetic peripheral neuropathy, shows that these complications go hand-in-hand in those patients [20].

In the group without diabetes (control subjects), all the three Vata, Pitta, and Kapha dominant Prakriti individuals were detected. The height, weight, BMI, and waist-hip ratio were higher in Kapha than Pitta and lowest in Vata Prakriti. According to Ayurveda, Vata Prakriti individuals are lean, thin, and short stature. In contrast, Kapha Prakriti individuals have well-shaped, well-developed, and compact bodies, which may be responsible for the lower height and weight of the Vata individuals than Kapha Prakriti individuals [15]. Singh et al. (2013) noted maximum BMI in Kapha Prakriti individuals while minimum in Vata Prakriti individuals [21]. This finding confirms the present study; our results were also supported by the study of Tiwari and Gehlot (2015) [22] and Patel et al. (2012) [13].

Furthermore, systolic and diastolic blood pressure was highest in Vata than Pitta and least in Kapha Prakriti individuals; however, it is within the physiological limits. Vata 
dominant Prakriti patients had a relatively higher physiological limit of blood pressure. As per the concepts of Ayurveda, vitiated Vyana Vata (a type of body Dosha, running all over the body, responsible for blood circulation) may be responsible for the rise in blood pressure [23]. The values of blood sugar levels were also found higher in Kapha than Pitta and Vata Prakriti but within the physiological limit. Individuals with a Kapha Prakriti had a higher lipid profile than those with a Pitta Prakriti, whereas those with a Vata Prakriti had the lowest. These findings are supported by research by Kahatri and Sharma (2013) [24]. Moreover, serum creatinine level is higher in Kapha Prakriti individuals than Pitta and Vata Prakriti subjects. eGFR also showed a similar relation as serum creatinine, supported by a study by Amin and Sharma (2015) [17].

Anthropometric and biochemical indicators were shown to correlate significantly with Prakriti types in patients with diabetes and without diabetes. Individuals' age and gender impact biochemical parameters, but we focused on Prakriti-based alterations in this study; even after accounting for the general impact of age and gender, Prakriti-wise substantial differences were discovered. Most diabetes-related metrics have a strong connection in Kapha Prakriti, indicating that Kapha Prakriti individuals are more prone to disease than other Prakriti types. This association is more precise when using discriminant function analysis on a few key contributing characteristics, resulting in a case and control group classification accuracy of over $90 \%$. The current study produced a mathematical model that may be utilized to predict individuals with or without diabetes based on their waist-hip ratio, postprandial blood sugar, and serum creatinine (the three key contributing parameters of the present study) as their Prakriti types. In the current investigation, these three primary contributing characteristics were strongly linked to the onset of diabetes. In addition, central obesity is directly linked with a higher waist-hip ratio, higher postprandial blood sugar, and serum creatinine, all of which are associated with improper metabolism, which is the leading cause of T2DM.

\section{Conclusions}

This study found a positive association between various biochemical and anthropometric parameters related to Prakriti types of individuals in both case and control groups. Individuals Prakriti and a few key contributing characteristics associated with the disease could be exploited as Prakriti-based biochemical markers. In addition, a mathematical model was developed based on Prakriti and a few significant contributing characteristics to predict individuals with and without diabetes, which is a preliminary study in this approach. Prior awareness of Prakriti prone to particular diseases can aid in disease prevention in the early stages. The finding can be used to modify patients' diet, lifestyles, and various medications to help them recover swiftly from illness. The decoding of the Ayurvedic concept of Prakriti could lead to global acceptance of Ayurvedic vocabulary.

In prospect of the present study, we believe that incorporating ancient Ayurvedic knowledge of Prakriti and the related concept of disease manifestation could benefit practitioners and the current healthcare system. Understanding Prakriti-based biochemical markers may open new avenues for scientific research into disease prognosis and treatment selection.

Supplementary Materials: The following supporting information can be downloaded at: https: / / www.mdpi.com/article/10.3390/diseases10010015/s1, Table S1 contains a brief overview of the Prakriti assessment tool; Table S2: Comparison of Kapha Prakriti between individuals with diabetes and without diabetes; Table S3: Comparison of Pitta Prakriti between individuals with diabetes and without diabetes.

Author Contributions: S.S. had performed the research work and drafted the original article. S.G. contributed to designing and drafting the article. N.K.A. provided desired subjects per the study criteria from his OPD and contributed to drafting the manuscript. G.S., biostatistician, performed the data analysis. S.K.S. critically reviewed and edited the article. R.S. conceptualized, critically examined, and edited the final manuscript. All authors have read and agreed to the published version of the manuscript. 
Funding: This research received no external funding.

Institutional Review Board Statement: The Research work has also been approved by the Institute of Medical Sciences Ethics Committee vide letter No. Dean/2015-2016/1572 dated 30 December 2015

Informed Consent Statement: Written informed consent from each participant was taken.

Data Availability Statement: This article includes the data generated and analyzed in this study.

Acknowledgments: The authors would like to express their gratitude to the attendants and resident doctors from OPD of Department Endocrine and Metabolism. The authors also wish to extend thanks to Vandana Verma for her assistance in the Prakriti assessment and, most importantly, all the subjects for participating in this work.

Conflicts of Interest: The authors declare no conflict of interest.

Limitation: The study covers a population of eastern Uttar Pradesh, India only. In the future, to obtain more precise results, the study may be conducted with a large sample size, and samples may be collected from a different area of the country or worldwide.

\section{References}

1. Singh, S.K.; Apata, T.; Singh, S.; McFadden, M.; Singh, R. Clinical Implication of Metformin in Relation to Diabetes Mellitus and Ovarian Cancer. Biomedicines 2021, 9, 1020. [CrossRef] [PubMed]

2. $\quad$ Long, J.; Liang, R.; Zheng, Q.; Yuan, G.; Xin, Z.; Chen, X.; Lai, F.; Liu, Y. Overview of Clinical Trials on Type 2 Diabetes Mellitus: A Comprehensive Analysis of the ClinicalTrials.gov Database. Diabetes Metab. Syndr. Obes. 2021, 14, 367-377. [CrossRef] [PubMed]

3. Harris, M.I. Impaired glucose tolerance in the U.S. population. Diabetes Care 1989, 12, 464-474. [CrossRef] [PubMed]

4. Stumvoll, M.; Goldstein, B.J.; van Haeften, T.W. Type 2 diabetes: Principles of pathogenesis and therapy. Lancet 2005, 365, 1333-1346. [CrossRef]

5. King, G.L. The role of inflammatory cytokines in diabetes and its complications. J. Periodontol. 2008, 79, 1527-1534. [CrossRef]

6. Singh, S.; Gehlot, S.; Agrawal, N.K. Basis of Disease Manifestation: A Molecular and Ayurvedic Approach with an Integrated Concept of Ayurgenomics. Inform. J. 2019, 19, 41-55. [CrossRef]

7. Aggarwal, S.; Negi, S.; Jha, P.; Singh, P.K.; Stobdan, T.; Pasha, M.A.; Ghosh, S.; Agrawal, A.; Prasher, B.; Mukerji, M. EGLN1 involvement in high-altitude adaptation revealed through genetic analysis of extreme constitution types defined in Ayurveda. Proc. Natl. Acad. Sci. USA 2010, 107, 18961-18966. [CrossRef]

8. Rizzo-Sierra, C.V. Ayurvedic genomics, constitutional psychology, and endocrinology: The missing connection. J. Altern. Complement. Med. 2011, 17, 465-468. [CrossRef]

9. Amin, H.; Sharma, R.; Vyas, M.; Vyas, H. Genomic Counterparts to Human Constitution (Prakriti). Indian J. Anc. Med. Yoga 2014, 7, 29-37.

10. Sharma, H.; Chandola, H.M. Prameha in Ayurveda: Correlation with obesity, metabolic syndrome, and diabetes mellitus. Part 1-etiology, classification, and pathogenesis. J. Altern. Complement. Med. 2011, 17, 491-496. [CrossRef]

11. Prasher, B.; Negi, S.; Aggarwal, S.; Mandal, A.K.; Sethi, T.P.; Deshmukh, S.R.; Purohit, S.G.; Sengupta, S.; Khanna, S.; Mohammad, F.; et al. Whole genome expression and biochemical correlates of extreme constitutional types defined in Ayurveda. J. Transl. Med. 2008, 6, 48. [CrossRef] [PubMed]

12. Amin, H.; Sharma, H. Biochemical and Anthropometric Profiles of Different Prakriti (Ayurvedic Constitution) Patients of Non-insulin Dependent Diabetes Mellitus. J. Obes. Metab. Res. 2015, 2, 120-124. [CrossRef]

13. Kavita, P.; Sangeeta, G.; Kamlakar, T. Effect of aerobic exercise on anthroprometric and metabolic parameters in Obese type-2 diabetics with reference to specific body constitution (prakriti). Int. J. Res. Ayurveda Pharm. 2012, 3, 659-663. [CrossRef]

14. Tripathi, P.K.; Gehlot, S. Development, Validation and Confirmation of an Archetype Tool to Evaluate Prakriti. J. Nat. Remedies 2019, 19, 206-213. [CrossRef]

15. Shilpa, S.; Venkatesha Murthy, C.G. Understanding personality from Ayurvedic perspective for psychological assessment: A case. Ayu 2011, 32, 12-19. [CrossRef]

16. Liese, A.D.; Mayer-Davis, E.J.; Tyroler, H.A.; Davis, C.E.; Keil, U.; Duncan, B.B.; Heiss, G. Development of the multiple metabolic syndrome in the ARIC cohort: Joint contribution of insulin, BMI, and WHR. Atherosclerosis risk in communities. Ann. Epidemiol. 1997, 7, 407-416. [CrossRef]

17. Amin, H.; Sharma, R. Biochemical and anthropometric profile of obese subjects of different Prakriti (Constitution) at Jamnagar District, Gujarat, India. Int. J. Clin. Exp. Physiol. 2015, 2, 16-22. [CrossRef]

18. Bhushan, P.; Kalpana, J.; Arvind, C. Classification of human population based on HLA gene polymorphism and the concept of Prakriti in Ayurveda. J. Altern. Complement. Med. 2005, 11, 349-353. [CrossRef]

19. Mahalle, N.P.; Kulkarni, M.V.; Pendse, N.M.; Naik, S.S. Association of constitutional type of Ayurveda with cardiovascular risk factors, inflammatory markers and insulin resistance. J. Ayurveda Integr. Med. 2012, 3, 150-157. [CrossRef]

20. Bansal, D.; Gudala, K.; Muthyala, H.; Esam, H.P.; Nayakallu, R.; Bhansali, A. Prevalence and risk factors of development of peripheral diabetic neuropathy in type 2 diabetes mellitus in a tertiary care setting. J. Diabetes Investig. 2014, 5, 714-721. [CrossRef] 
21. Singh, P.K.; Byadgi, P.S.; Singh, G.; Tripathi, N.S. Impact of season and constitution on lipid parameters. Ayu 2013, 34, 77-80. [CrossRef] [PubMed]

22. Tiwari, S.; Gehlot, S. Variation of bmi as per prakriti in diabetic and hypertensive Individuals by walking. Int. Ayurvedic Med. J. 2015, 3, 1718-1723.

23. Bhalerao, S.; Deshpande, T.; Thatte, U. Prakriti (Ayurvedic concept of constitution) and variations in platelet aggregation. BMC Complement. Altern. Med. 2012, 12, 248. [CrossRef] [PubMed]

24. Khatri, M.; Sharma, U.S. A comparative study of changes in lipid profile in different age groups W.S.R. prakriti. Int. J. Ayurveda Pharma Res. 2013, 1, 31-37. 